Article

\title{
Effects of Pulsed Electric Fields (PEF) on Vitamin C and Its Antioxidant Properties
}

\author{
Zhi-Hong Zhang ${ }^{1}$, Xin-An Zeng ${ }^{1, *}$, Charles S. Brennan ${ }^{1,2, *}$, Margaret Brennan ${ }^{2}$, Zhong Han ${ }^{1}$ \\ and Xia-Yu Xiong 1
}

1 College of Light Industry and Food Science, South China University of Technology, Guangzhou 510640, China; E-Mails: zhihong1942@foxmail.com (Z.-H.Z.); fezhonghan@scut.edu.cn (Z.H.); hsiungxiayu@163.com (X.-Y.X.)

2 Centre for Food Research and Innovation, Department of Wine, Food and Molecular Biosciences, Lincoln University, Lincoln 85084, New Zealand; E-Mail: margaret.brennan@lincoln.ac.nz

* Authors to whom correspondence should be addressed;

E-Mails: xazeng@scut.edu.cn (X.-A.Z.); charles.brennan@lincoln.ac.nz (C.S.B.);

Tel./Fax: +86-20-3938-1192 (X.-A.Z.).

Academic Editor: Maurizio Battino

Received: 26 August 2015 / Accepted: 7 October 2015 / Published: 13 October 2015

\begin{abstract}
In this study, pulsed electric fields (PEF) treatments and their effects on the structure of vitamin C (VIT-C) were estimated by fluorescence and Fourier transform infrared (FT-IR) spectroscopy, the relative content of VIT-C was measured by HPLC and the antioxidant properties of treated VIT-C by DPPH radical scavenging as well as reducing power tests. The fluorescence intensity of treated VIT-C increased slightly compared to the untreated VIT-C. Moreover, the effect of PEF on the structure of VIT-C was observed using the FT-IR spectra. These phenomena indicated that the PEF affected the conformation of VIT-C, which promoted the VIT-C isomer transformed enol-form into keto-form. In addition, the PEF treatments did not suffer the damage to VIT-C and could slow down the oxidation process in involving of experimental conditions by HPLC. The antioxidant properties of the treated VIT-C were enhanced, which was proved by radical scavenging and also the reducing power tests.
\end{abstract}

Keywords: vitamin C; PEF; fluorescence; FTIR; HPLC; antioxidant properties 


\section{Introduction}

Vitamins are a diverse group of essential organic compounds that participate in normal growth, metabolism and maintenance of life [1,2]. In order to maintain an adequate intake of vitamins, humans must eat a wide variety of food products, either naturally high or, enriched with vitamins or alternatively supplement with multivitamin drugs, because the human body cannot synthesize them or the synthetic amount may not satisfy the bodily needs. Vitamin C (VIT-C) or L-ascorbic acid (AA) is an essential water-soluble vitamin in humans [3,4]. Humans lack the final enzyme (L-gulono-1,4-lactone oxidase) in the VIT-C biosynthesis pathway, thus, humans are dependent on fruits and vegetables (such as orange, sweet potato, and carrot) in their diet to provide VIT-C [5,6]. Vitamin C is beneficial for its antioxidant capacity and stimulation of immune system [7-9].

Although most vegetables and fruits contain certain amount of VIT-C, various storage conditions and processing methods can significantly affect VIT-C content [10], because VIT-C is a thermally sensitive bioactive nutrient when in the presence of oxygen [11-16]. Some advanced non-thermal methods, therefore are used in fruit and vegetable processing in order to maintain nutrition, such as ultra-high pressure processing (UHP) [17,18], pulsed electric fields (PEF) [19-21].

PEF technology involves the application of very short pulses $(1-10 \mu \mathrm{s})$ of high electric intensity $(10-100 \mathrm{kV} / \mathrm{cm})$ to treat food products placed between two electrodes without substantially heating the product $[22,23]$. Nowadays, it is one of the hot points regarding the effect of PEF technology on nutrient, especially, vitamins and polyphenols [11-13,24]. Ade-Omowaye et al. [25] showed that the VIT-C retention of red bell pepper immediately after PEF treatment ( 50 pulses at $2 \mathrm{kV} / \mathrm{cm}$, pulse duration $400 \mathrm{~ms}$ ) ranged from $89.6 \%$ to $96.5 \%$. Odriozola-Serrano et al. [20] observed that the VIT-C retention of strawberry juice was $98 \%$ after High Intensity Pulse Electric Field (HIPEF) $(35 \mathrm{kV} / \mathrm{cm}, 1000 \mu \mathrm{s}$, and monopole mode). Moreover, they found that VIT-C retention was related to some parameters in terms of frequency, electric field intensity, pulsed width and polarity mode by a response surface methodology. In addition, many studies have proven that the retention of VIT-C was higher after PEF treatments than after thermal treatments $[20,21,26]$. In previous studies, it has been reported that the PEF-processing resulted in increased VIT-C retention when compared to other thermal treatments [20,21,27].

As mentioned above, there are some ambiguous results in effect of PEF treatment on VIT-C properties in previous studies. In addition, the complex food structures of fabricated foods have made it difficult to determine the effect of PEF treatment on the VIT-C. Relatively few studies mentioned that the PEF treatment directly affected the VIT-C. To solve the problem, systematically characterizing the effect of PEF treatment involved in different electric field strength and treatment time on the structure of VIT-C by fluorescence and Fourier transform infrared (FT-IR) spectroscopy is attempted. Moreover, the effect of PEF treatment on relative content of VIT-C was determined by high performance liquid chromatography (HPLC) and the antioxidant properties were measured by DPPH radical scavenging and the reducing power test. 


\section{Results and Discussion}

\subsection{Fluorescence of VIT-C}

The effects of different electric field strength and treatment time on fluorescence of VIT-C are shown in Figures 1 and 2, respectively. Previously researchers have illustrated that the condensation product emits strong fluorescence and that the detection limit is very low $(0.006 \mu \mathrm{g} / \mathrm{mL})$ [28]. Therefore, fluorescence of VIT-C was determined based on the condensation reaction between VIT-C and $o$-phenylenediamine. This method can not only determine the content of VIT-C, but also observe the effects of PEF on the structure of VIT-C. It was observed that the fluorescence intensity of PEF treated VIT-C was higher than untreated VIT-C at $405 \mathrm{~nm}$, and showed a tendency that the higher electric field strength was corresponding to the stronger fluorescence intensity. Moreover, the PEF treatment time also affected the fluorescence intensity of VIT-C. The fluorescence intensity of VIT-C treated by 3, 9, 15, 21 and $27 \mathrm{~min}$ (the effective PEF treatment was 0.8, 2.4, 4.0, 5.6, and 7.2 ms) were higher than the untreated $(0 \mathrm{~ms})$ sample at $405 \mathrm{~nm}$, and the fluorescence intensity gradually increased with the treatment time. This phenomenon indicated that the PEF treatment could exert influence on the condensation reaction process of VIT-C and $o$-phenylenediamine, which is due to the type of VIT-C isomer present.

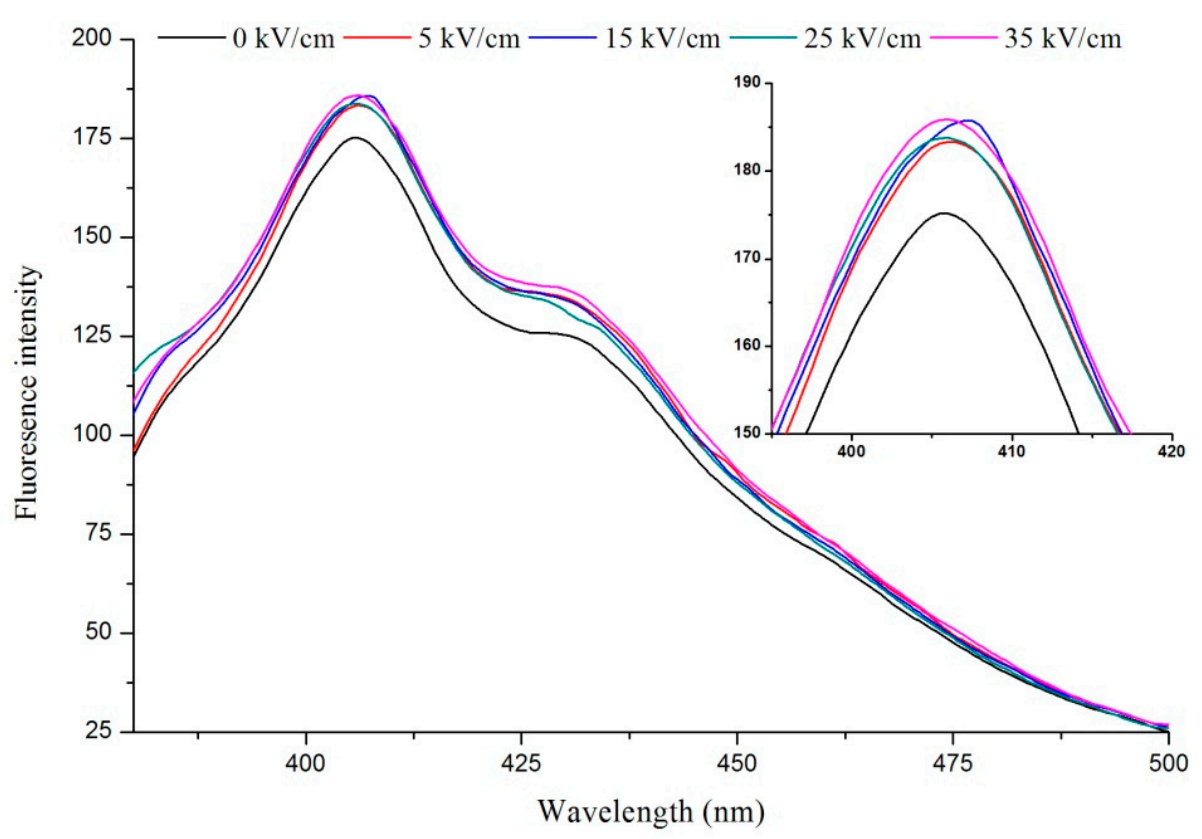

Figure 1. The effect of different electric field strength at $9 \mathrm{~min}$ on fluorescence of vitamin C (VIT-C). 


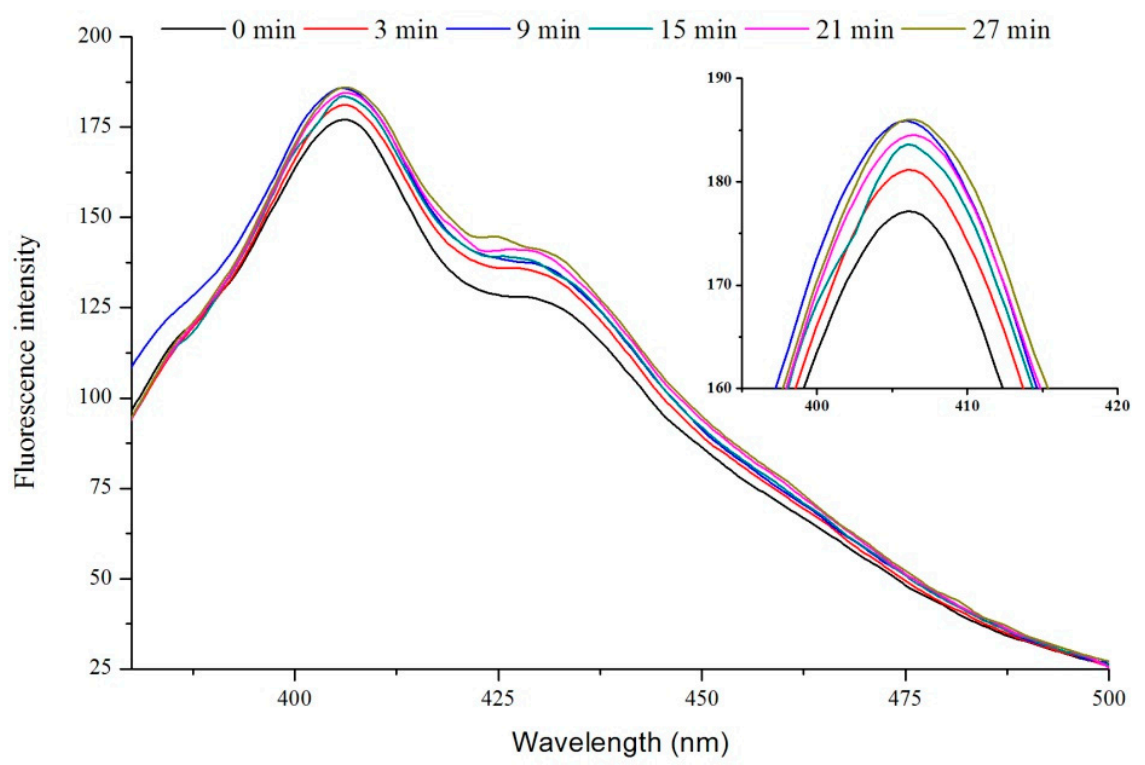

Figure 2. The effect of different pulsed electric fields (PEF) treatment time at $35 \mathrm{kV} / \mathrm{cm}$ electric field strength on fluorescence of VIT-C.

Wu et al. (2003) [28] reported that hydroxyl ion $(-\mathrm{OH})$ could promote the conversion of VIT-C isomer from enol-form to keto-form in the range of $\mathrm{pH} 9.3-9.5$, which proved that alkaline condition was conducive to the condensation reaction. In this study, the reaction system was under acidic conditions ( $\mathrm{pH}<7.0)$, but the fluorescence intensity was increased by PEF treatment, which indicated that PEF treatment promoted the conversion of VIT-C isomer. It has been reported that the water molecule was easily polarized by PEF and was dissociated into ions at high field strength [29]. The presence of polar groups can react with the interior macromolecules or active ingredients. Zhang et al. [30] reported that the PEF processing generated hydrogen radicals in phosphate buffer and oleic acid emulsion, they also illustrated that the electric field strength had a significant effect on $\mathrm{H}_{2} \mathrm{O}_{2}$ concentrations $(p<0.5)$ when estimated using electron spin resonance (ESR) techniques. Thus, it was believed that the free radicals generated by PEF treatment attacked the hydroxyl, which belonged to the VIT-C second carbon atom to complete the conversion of configuration. The possible mechanism is illustrated in Figure 3. This theory was consistent with the experimental phenomenon of VIT-C degradation by PEF processing in previous studies [21,31]. Moreover, some previous studies reported that the PEF treatment could influence the structure of amino acids, proteins and polysaccharides, which mainly related to the weak bonds such as hydrogen bonds, disulfide bonds and hydrophobic bonds [32-34].

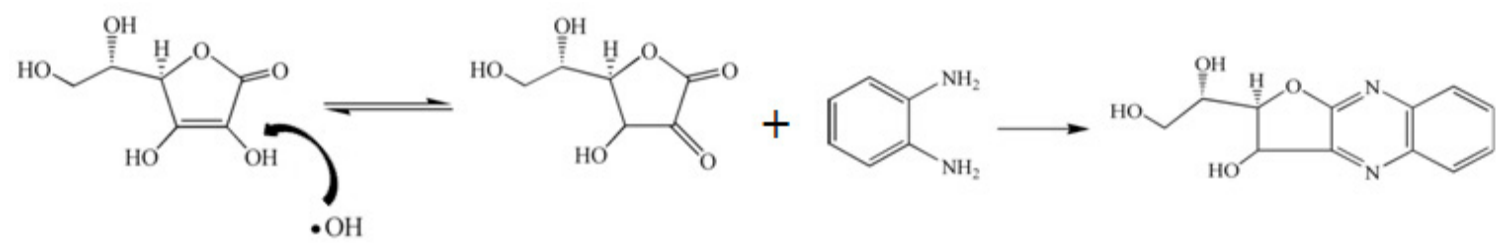

Figure 3. The possible mechanism of condensation reactions of VIT-C with $o$-phenylenediamine by PEF treatments. 


\subsection{FT-IR Analysis}

The FT-IR spectra of PEF treated VIT-C solution are shown in Figure 4. The infrared spectroscopy characteristic absorption band of the VIT-C mainly appeared in wavenumber as follows. The band at $1600 \mathrm{~cm}^{-1}$ is contributes to vibration of $\mathrm{C}=\mathrm{C}$ bonds. The band at $1680 \mathrm{~cm}^{-1}$ causes vibration of the $\mathrm{C}=\mathrm{O}$ area present in the lactone ring system. Data presented in this manuscript illustrates that the stretching vibration of $\mathrm{C}=\mathrm{C}$ and $\mathrm{C}=\mathrm{O}$, respectively, appeared at about 1700 and $1660 \mathrm{~cm}^{-1}$ by FT-IR spectra recorded in $\mathrm{KBr}$ pellets, this is consistent with previous studies when the effect of the solvent is taken into consideration $[35,36]$.

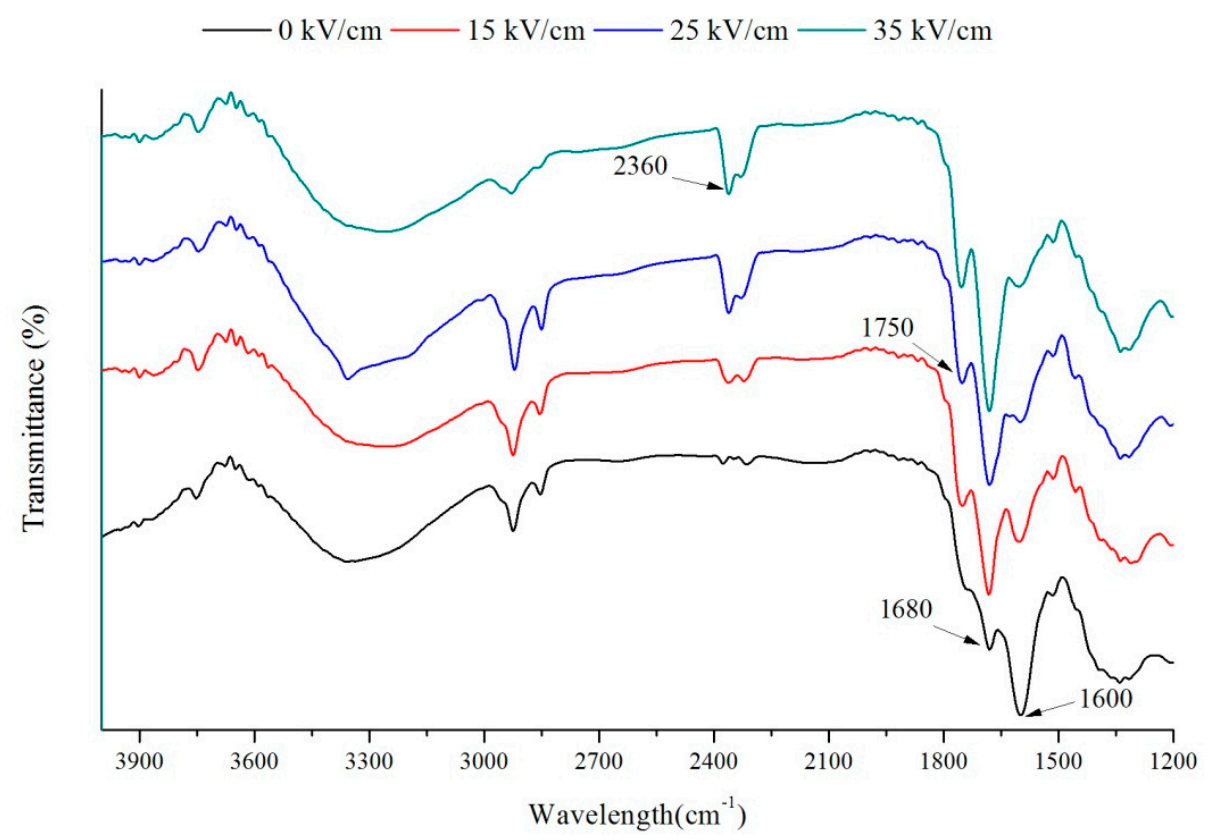

Figure 4. Fourier transform infrared (FTIR) spectra of VIT-C solution by PEF treatments.

The characteristic absorption band of the VIT-C showed some changes due to PEF treatment from the FT-IR spectra. When the electric field strength increased, the intensity of the band at $1600 \mathrm{~cm}^{-1}$ decreased, while the intensity of the band at $1680 \mathrm{~cm}^{-1}$ increased compared with untreated VIT-C. This phenomenon indicated that the structure of VIT-C has been transformed from the enol-form to keto-form by PEF treatment. Moreover, an obvious absorption peak was located at the band of $2360 \mathrm{~cm}^{-1}$, which was attributed to the $\mathrm{O}-\mathrm{H}$ stretching vibration. It indicates that the hydrogen atom from the $\mathrm{O}-\mathrm{H}$ on third carbon was generated with carbonyl on second carbon atom bonded to a five membered ring system. Thus, it is believed that the PEF treatment could influence the structure of VIT-C from the FT-IR spectra. In addition, other previous studies also identified that the PEF could affect the structures of the protein and chitosan [37,38].

\subsection{The Relative Content of VIT-C}

When the PEF treatment affects the VIT-C content it is reflected through a change in the peak area of VIT-C by HPLC. The effect of PEF treatment on the relative content of VIT-C measured by HPLC is shown in Table 1. The relative content of PEF treated VIT-C was 97.56, 97.98, 93.60 
and $95.28 \mathrm{mg} / \mathrm{L}$ at $5,15,25$ and $35 \mathrm{kV} / \mathrm{cm}$ for $3 \mathrm{~min}$, which was apparently higher than the untreated VIT-C of $93.96 \mathrm{mg} / \mathrm{L}$. The results also showed that the VIT-C content of PEF treated samples was higher than the untreated VIT-C samples, also the untreated samples decreased in VIT-C over the increasing treatment time. This result was in agreement with the findings of Odriozola-Serrano et al. [21], who reported that the PEF treatment exhibited higher VIT-C retention than heat treatments in different fruits and vegetables juice. Moreover, some other studies showed that the $35 \mathrm{kV} / \mathrm{cm}$ of PEF treatment exhibited higher effectiveness on the retention of VIT-C than other selected electric field strengths [20] or thermal treatments [39,40]. The results showed that the content of VIT-C decreased with the increasing treatment time under 5 and $15 \mathrm{kV} / \mathrm{cm}$, which was in agreement with the finding of Elez-Martinez and Martin-Belloso [41]. Meanwhile, a very interesting phenomenon was noted at $35 \mathrm{kV} / \mathrm{cm}$ and that was that the relative content of VIT-C increased from 95.28 to $98.14 \mathrm{mg} / \mathrm{L}$ as time increased from 3 to $27 \mathrm{~min}$. A previous study reported that the ascorbic acid of orange-carrot juice decreased from $25.07 \pm 0.68$ to $22.53 \pm 1.192 \mathrm{mg} / 100 \mathrm{~mL}$ with an increase in treatment time from 90 to $200 \mu \mathrm{s}$ at $35 \mathrm{kV} / \mathrm{cm}$ [31]. The reason for this phenomenon may be due to the difference of the reaction conditions such as $\mathrm{pH}$, electrical conductivity and temperature. These results indicate that whether using PEF treatment or not, the content of VIT-C could reduce as a consequence of extending the processing time which can be due to the natural oxidation of VIT-C. Moreover, the PEF treatments did not cause the damage to VIT-C and were able to retard the oxidation process under the experimental conditions created.

Table 1. The effect of PEF treatment on the relative content of VIT-C as detected by HPLC.

\begin{tabular}{|c|c|c|c|c|c|}
\hline Relative Content (mg/L) & $0 \mathrm{kV} / \mathrm{cm}$ & $5 \mathrm{kV} / \mathrm{cm}$ & $15 \mathrm{kV} / \mathrm{cm}$ & $25 \mathrm{kV} / \mathrm{cm}$ & $35 \mathrm{kV} / \mathrm{cm}$ \\
\hline $3 \mathrm{~min}$ & $93.69 \pm 0.12 \mathrm{~A} \mathrm{a}$ & $97.56 \pm 0.10^{\text {В С а }}$ & $97.98 \pm 0.38^{\mathrm{Ca}}$ & $93.60 \pm 0.81 \mathrm{~A} \mathrm{a}$ & $95.28 \pm 0.24 \mathrm{Da}$ \\
\hline $9 \min$ & $92.85 \pm 0.23 \mathrm{Ab}$ & $98.12 \pm 0.31^{\mathrm{Bab}}$ & $97.96 \pm 0.50^{\mathrm{B} \mathrm{a}}$ & $96.77 \pm 0.24^{\mathrm{Cb}}$ & $96.30 \pm 0.56^{\mathrm{Ca}}$ \\
\hline $15 \mathrm{~min}$ & $91.72 \pm 0.41 \mathrm{Ac}$ & $98.53 \pm 0.27^{\text {В b }}$ & $97.77 \pm 0.43 \mathrm{~B} \mathrm{a}$ & $98.45 \pm 0.62^{\mathrm{B} \mathrm{c}}$ & $96.50 \pm 0.70^{\mathrm{Ca}}$ \\
\hline $21 \mathrm{~min}$ & $91.51 \pm 0.15^{\mathrm{Ac}}$ & $97.43 \pm 0.42$ В а & $97.59 \pm 0.41 \mathrm{~B} \mathrm{а}$ & $98.33 \pm 0.47^{\mathrm{Bc}}$ & $98.19 \pm 0.53^{\text {В b }}$ \\
\hline $27 \mathrm{~min}$ & $91.38 \pm 0.22^{\mathrm{Ac}}$ & $95.12 \pm 0.51^{\mathrm{B} \mathrm{c}}$ & $97.32 \pm 0.35^{\mathrm{Ca}}$ & $98.01 \pm 0.53 \mathrm{Cbc}$ & $98.14 \pm 0.42^{\mathrm{Cb}}$ \\
\hline
\end{tabular}

PEF: pulsed electric fields; VIT-C: vitamin C. Values with different letters in the column (a-c) and in the row (A-D) mean significant difference $(p<0.05)$.

\subsection{1,1-Diphenyl-2-picrylhydrazyl (DDPH) Radical Scavenging Activity}

Figure 5 illustrates that the 1,1-diphenyl-2-picrylhydrazyl (DDPH) radical scavenging ability of PEF treated VIT-C increased compared to untreated VIT-C. The DDPH radical scavenging of VIT-C was $87.84 \%, 91.89 \%, 89.99 \%$ and $89.32 \%$, respectively, with $5,15,25$ and $35 \mathrm{kV} / \mathrm{cm}$ of PEF treatment for $15 \mathrm{~min}$; these were all a significant increase compared with untreated VIT-C, which had a DDPH radical scavenging activity of $83.28 \%(p<0.05)$. However, the DPPH radical scavenging activity that was treated for $3 \mathrm{~min}$ with different electric field strengths was not significantly different at $15-35 \mathrm{kV} / \mathrm{cm}$. This result indicated that the treatment time was obvious influence on the DPPH radical scavenging activity. As treatment time increased, the DPPH radical scavenging activity of non-treated VIT-C was obviously decreased, but the PEF treatment of VIT-C caused DPPH radical scavenging activity to show a trend of either no reduction or some increase. These results illustrated that the PEF treatment at appropriate electric field strength and treatment time could effectively maintain the activity of VIT-C. 
Similar results were found in a previous study by Wang and coworkers [38]. In this context, the antioxidant activity of glutathione (GSH) treated with different electric field intensities from 10 to $30 \mathrm{kV} / \mathrm{cm}$ were significantly increased, especially at the electric field strength of $10 \mathrm{kV} / \mathrm{cm}$. Other previous studies have also indicated that under certain electric field strengths, the structure of protein showed some changes, such as the molecular weight, the quaternary structure, and polarization of the proteins molecule, which caused the increase or decrease of the DDPH radical inhibition [42,43]. It can be shown that the PEF treatment influenced the structure of VIT-C in Sections 3.1 and 3.2, which may be one of the reasons for the increasing DPPH radical scavenging activity. In addition, the PEF treated solutions could exhibit the higher VIT-C retention $(95.12-98.53 \mathrm{mg} / \mathrm{L})$, which may be one of the reasons for enhancing the DPPH radical scavenging.

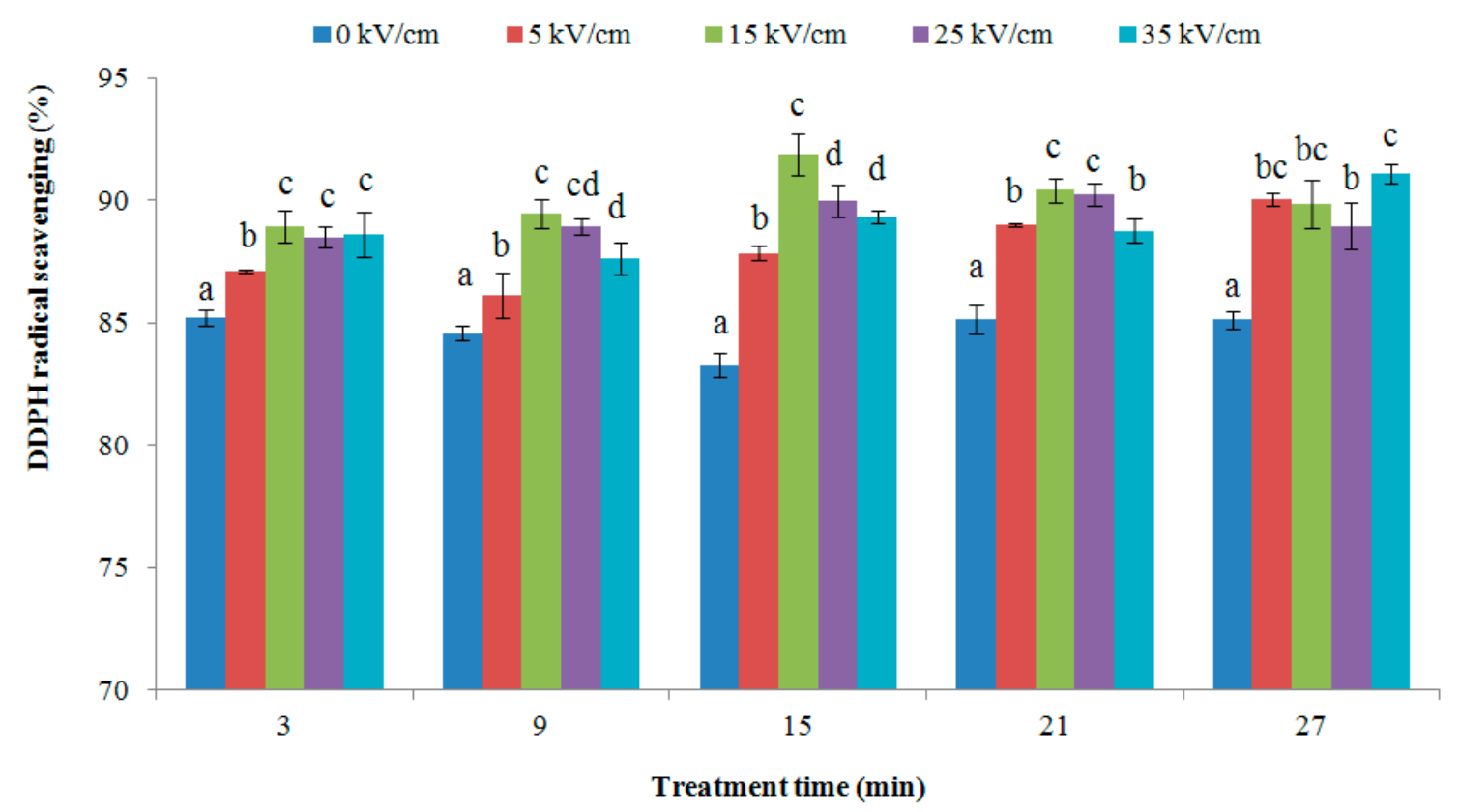

Figure 5. 1,1-diphenyl-2-picrylhydrazyl (DDPH) radical scavenging activity of VIT-C by PEF treatments. Values in columns followed by different letters mean significant difference $(p<0.05)$.

\subsection{Reducing Power Ability}

The reducing power activity of PEF treated VIT-C using the potassium ferricyanide reduction method is shown in Figure 6. The results were expressed as absorbance at $700 \mathrm{~nm}$. It is shown that the reducing power ability, by different electric field strengths based on 3 min treatment of PEF treated VIT-C, significantly increased as compared with non-treated VIT-C $(p<0.05)$, reducing power increased by $13.50 \%, 10.24 \%, 11.42 \%$, and $15.28 \%$ at $5,15,25$ and $35 \mathrm{kV} / \mathrm{cm}$, respectively. Among the different electric field strengths, however, there was no significant difference. At other processing times, the PEF treated VIT-C also showed a tendency for the reducing power ability to increase as compared to non-treated VIT-C. These results indicate that the reducing power of PEF treated VIT-C can be increased compared with non-treatment. The reason for this phenomenon was that the PEF treatment altered the structure and polarization of VIT-C. As a result, it is easier for the VIT-C to provide electrons, thereby the antioxidant capacity was enhanced; similar results were found in the previous study [44]. 
In this study, the treatment time was extended and the reducing power of peptides derived from egg white was increased by treatment with $10 \mathrm{kV} / \mathrm{cm}$ PEF. Notably, the reducing power was increased by 0.118 after a $5 \mathrm{~h}$ PEF treatment compared to an untreated sample of 0.646 . This result showed that the PEF treatment time could significantly increase the antioxidant activity of the peptides. It was believed that PEF treatment could activate the antioxidant activity of peptides derived from egg white by polarization of peptide molecules, and destroy the non-covalent bonds, by hydrophobic interactions, electrostatic interactions and creating hydrogen bonds [44]. In addition, a previous study observed the effects of different electrode materials on antioxidant capacity and other characteristics of cyaniding-3-glucoside (Cy-3-glc) and cyaniding-3-sophoroside (Cy-3-sop) during $10 \mathrm{kV} / \mathrm{cm}$ of PEF treatment. The results showed that the antioxidant of Cy-3-glc and Cy-3-sop was increased, regardless of the method used (FRAP, DDPH and ORAC), which was due to the higher retention of Cy-3-sop and Cy-3-glc, the electrochemical reaction and forming of anthocyanin-metal complexes that have higher antioxidant capacity [45].

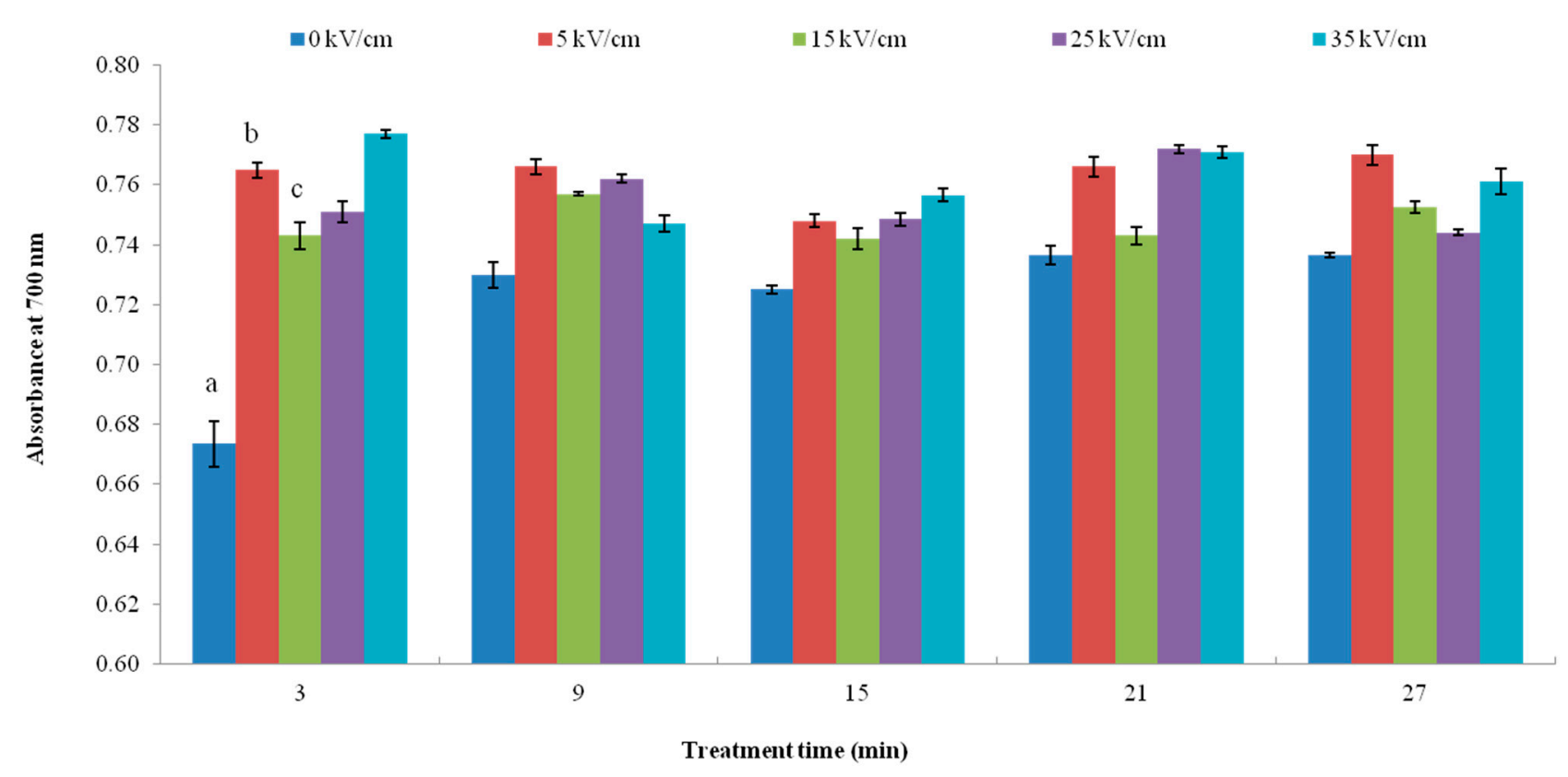

Figure 6. Reduce power activity of VIT-C by PEF treatments. Values in columns followed by different letters mean significant difference $(p<0.05)$.

\section{Materials and Methods}

\subsection{Materials}

Vitamin C and ethanol were purchased from Sinopharm Chemical Reagent Co., Ltd. (Shanghai, China). Potassium ferricyanide purchased from Tianjin Fuchen Chemical Reagent Factory (Tianjin, China). $O$-phenylenediamine was obtained from Tianjin Kemiou Chemical Reagent Co., Ltd. (Tianjin, China). Methanol was obtained from ANPEL Laboratory Technologies Inc. (Shanghai, China). 1,1-Diphenyl-2-picrylhydrazyl (DDPH radical) was obtained from Sigma-Aldrich, Chemie GmbH (St. Louis, MO, USA). All other reagents and chemicals used were of analytical grade. All reagents were prepared with deionized water (conductivity $0.3 \mu \mathrm{S} / \mathrm{cm}$ ). 


\subsection{PEF Treatment System}

The continuous PEF system was designed and manufactured by South China University of Technology PEF team (SY-Z-500; Guangzhou, China). The structure of the equipment has been reported in previous studies [46,47]. The main parameters of this equipment were as follows: frequency of $1 \mathrm{kHz}$, pulse width of $40 \mu \mathrm{s}$, unipolar square-wave. A two channel digital storage oscilloscope (DST1102B, Tekway Technologies Co., Ltd., Nanjing, China) was used to monitor the power supply of PEF system during the treatment. The treatment chamber was made of Teflon. The parameters of chamber were as follows: the volume of $0.02 \mathrm{~mL}$, the distance between two parallel titanium-based alloy electrodes of $0.3 \mathrm{~cm}$. The sample flow was controlled by a peristaltic pump (323 E/D, Watson Marlow, NC, USA). The sample temperature was measured by thermocouple (EW-981, Ewelly, Guangzhou, China) and was maintained by a cooling circulator (DLSK 3/10, Ketai Laboratory Equipment Co., Ltd., Zhengzhou, China). The scheme of the PEF treatment system used in the experiment is shown in Figure 7. In this study, $100 \mathrm{mg} / \mathrm{L}$ of VIT-C solution was prepared by ethanol-aqueous (volume ratio of 1:1) in a $1 \mathrm{~L}$ volumetric flask. The bubbles were removed by vacuum pump before the treatment. The $\mathrm{pH}$ of VIT-C solution was 4.47 and conductivity value was $10.0 \mathrm{mS} / \mathrm{cm}\left(20 \pm 1{ }^{\circ} \mathrm{C}\right)$. The flow rate of sample was set at $60 \mathrm{~mL} / \mathrm{min}$ by a peristaltic pump and the temperature was maintained at $20 \pm 1{ }^{\circ} \mathrm{C}$ by cooling circulator. According to Equations (1) and (2), the effective treatment time $(t)$ of PEF were calculated to be $0.8,2.4,4.0,5.6$ and $7.2 \mathrm{~ms}$ inthe different cycle times $(1,3,5,7$, and 9$)$, corresponding to the sample actual treatment time was 3, 9, 15, 21 and $27 \mathrm{~min}$, respectively. In addition, the selected electric field strengths were $0,0.5,12.5,25$ and $35 \mathrm{kV} / \mathrm{cm}$. The energy input $(Q)$ was calculated by Equation (3) as described by Han et al. [32], and the results are shown in Table 2. After PEF treatment, each sample was collected in a $10 \mathrm{~mL}$ glass test tube with stopper and stored at $4 \pm 1{ }^{\circ} \mathrm{C}$ until analysis could be carried out. The experiments were performed three times.

$$
\begin{gathered}
t=N_{t} \times W_{p} \times n \\
N_{t}=\frac{f \times V}{S}
\end{gathered}
$$

where $N_{t}$ is pulse number, $W_{p}$ represents pulse width $(\mu \mathrm{s}), n$ denotes sample cycles, $f$ represents pulse repetition rates, $V$ is the volume of the chamber $(\mathrm{mL})$ and $S$ is the flow rate $(\mathrm{mL} / \mathrm{s})$.

$$
Q=E^{2} \times t \times \delta
$$

where $Q$ is the energy input $\left(\mathrm{J} / \mathrm{m}^{3}\right), E$ is the electric field strength $(\mathrm{V} / \mathrm{m}), t$ is the treatment time and $\delta$ is the conductivity of the sample $(\mathrm{S} / \mathrm{m})$. 


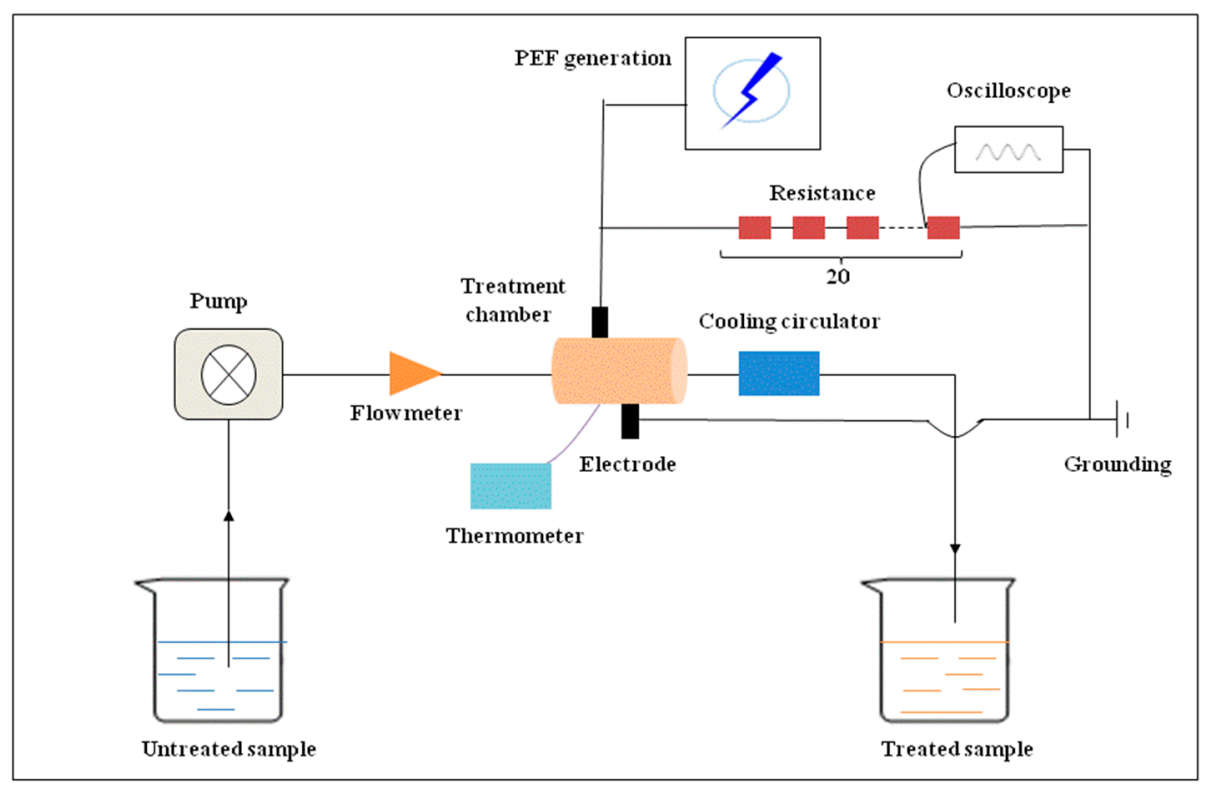

Figure 7. The scheme of the PEF treatment system used in the experiment.

Table 2. The energy input $\left(Q, \mathrm{~kJ} / \mathrm{cm}^{3}\right)$ of PEF in the different treatment condition.

\begin{tabular}{cccccc}
\hline \multirow{2}{*}{ Electric Field Strength $(\mathbf{k V} / \mathbf{c m})$} & \multicolumn{5}{c}{ Treatment Time (ms) } \\
\cline { 2 - 6 } & $\mathbf{0 . 8}$ & $\mathbf{2 . 4}$ & $\mathbf{4 . 0}$ & $\mathbf{5 . 6}$ & $\mathbf{7 . 2}$ \\
\hline 5 & 0.05 & 0.15 & 0.25 & 0.35 & 0.45 \\
15 & 0.45 & 1.35 & 2.25 & 3.15 & 4.05 \\
25 & 1.25 & 3.75 & 6.25 & 8.75 & 11.25 \\
35 & 2.45 & 7.35 & 12.25 & 17.15 & 22.05 \\
\hline
\end{tabular}

\subsection{Fluorescence Measurement}

The determination of VIT-C was performed as described by Wu et al. [28] with some modifications. The VIT-C content was determined by a spectrofluorometer (Perkin-Elmer LS55, Beaconsfield, Bucks, UK). Briefly, $0.5 \mathrm{~mL}$ of sample was added to $4.5 \mathrm{~mL}$ of ethanol-aqueous (volume ratio of 1:1), and then mixed with $0.5 \mathrm{~mL} o$-phenylenediamine solution $(0.2 \mathrm{~g} / \mathrm{L})$. The mixture was placed in dark and allowed to stand for $30 \mathrm{~min}$. Fluorescence intensities of samples were determined in a $1 \mathrm{~cm}$ quartz cell (excitation and emission wavelengths of 355 and $405 \mathrm{~nm}$, respectively). Width of excitation and emission slit were both set at $10 \mathrm{~nm}$, and the relative fluorescence was determined.

\subsection{FT-IR Analysis}

Spectrometry analysis of the VIT-C solutions by PEF treatment was carried out to observe the structure by using an FT-IR spectrometer (Vector33, Bruker, Ettlingen, Germany). The samples were fixed in the $\mathrm{CaF}_{2}$ window and FTIR spectra were collected in the range of $1100-4000 \mathrm{~cm}^{-1}$.

\subsection{Determination of VIT-C by HPLC}

The relative content of VIT-C was determined using Waters 1525 Binary HPLC (Waters Corp., Milford, MA, USA) equipped with a $\mathrm{C}_{18}$ column $(250 \times 4.0 \mathrm{~mm}, 5 \mu \mathrm{m}$, SunFire, Waters, Milford, MA, 
USA), an autosampler (2707, Waters, Milford, MA, USA) and a photodiode array detector (2998, Waters, Singapore). The method described by Klimczak and Gliszczyńska-Świgło [48] with some modifications. A gradient of mobile phase composed of water (solvent A) and methanol (solvent B) was used $10 \% \mathrm{~A}$ in $15 \mathrm{~min}$ with the flow rate of $0.8 \mathrm{~mL} / \mathrm{min}$. The eluate was detected by UV detection at $245 \mathrm{~nm}$. The injection volume was $20 \mu \mathrm{L}$.

\subsection{DDPH Radical Scavenging Activity}

The antioxidant activity of VIT-C solutions was determined by a stable capacity DDPH radical following the method described by Gu et al. [49] with some modifications. Sample (200 mL) was mixed with $3.5 \mathrm{~mL}$ of $0.1 \mathrm{mmol} / \mathrm{L}$ DPPH solution (DPPH was dissolved in ethanol) and vortexed for mixing before leaving the samples to stand for $20 \mathrm{~min}$ in the dark. Absorbance values were determined at $517 \mathrm{~nm}$ using a spectrophotometer (UV-1800, SHIMADZU, Tokyo, Japan). DPPH activity was calculated by the following Equation (4).

$$
\mathrm{SA}(\%)=\left(1-\frac{\mathrm{A}_{1}-\mathrm{A}_{2}}{\mathrm{~A}_{3}}\right) \times 100
$$

where SA is the scavenging activity DDPH radical. $A_{1}$ is the absorbance of the sample. $A_{2}$ is the absorbance of the blank. $\mathrm{A}_{3}$ is the absorbance of the control.

\subsection{Reducing Power Ability}

The reducing power of sample was determined by the method of Yen et al. [50] with some modifications. The sample solutions were mixed with $2.5 \mathrm{~mL}$ of $0.2 \mathrm{~mol} / \mathrm{L}$ phosphate buffer ( $\mathrm{pH}$ 6.6) and $2.5 \mathrm{~mL}$ of $1 \%$ potassium ferricyanide. Each sample solution was incubated for $20 \mathrm{~min}$ at $50{ }^{\circ} \mathrm{C}$ and then cooled to room temperature. Trichloroacetic acid $(2.5 \mathrm{~mL})$ was added to each sample, followed by vigorous mixing. An aliquot of $2.5 \mathrm{~mL}$ of each sample was mixed $0.5 \mathrm{~mL}$ of $1 \mathrm{~g} / \mathrm{L}$ ferric chloride and the absorbance of the resultant solution was measured at $700 \mathrm{~nm}$. Higher absorbance of the reaction mixture indicated greater reducing power.

\subsection{Statistical Analysis}

All results were reported as mean \pm standard deviation $(n=3)$ using SPSS 16.0 software (IBM, New York, NY, USA). Variance analysis and graphs were obtained by Origin 8.0 software (OriginLab, Massachusetts, MA, USA) to determine the different treatment variations. Significance testing was performed by Tukey's multiple-comparison test and the differences were statistically significant. The significance level was $5 \%(p<0.05)$ unless otherwise stated.

\section{Conclusions}

The effects of PEF treatment on VIT-C structure, and its relative content and antioxidant properties were investigated in this study. The fluorescence intensity increased by PEF treatment as compared to the non-treated VIT-C using the fluorescence measurement. This result indicated that the PEF treatment could modify the molecular conformation of VIT-C (from enol-form to keto-form). FT-IR spectra 
proved the changes of VIT-C structure by PEF treatment. Moreover, the PEF treatments did not damage the VIT-C and could slow down the oxidation process in involving of experimental conditions. In addition, PEF treatment could enhance the antioxidant properties through the DPPH radical scavenging and reducing power test, which could be due to the structure changes of VIT-C. The antioxidant properties showed that the DPPH radical scavenging was significantly increased by $4.56 \%, 8.61 \%, 6.71 \%$, and $6.04 \%$, respectively, which were corresponding to $5,15,25$, and $35 \mathrm{kV} / \mathrm{cm}$ under 3 min processing time compared to the non-treated VIT-C $(p<0.05)$.

\section{Acknowledgments}

This research was supported by "863 project" (2011AA100801), National Natural Science Foundation of China (21376094 and 31301559) and Science and Technology Projects of Guangdong Province (2012A020200002, 2012A020100005 and 2013B020311008). The authors are also grateful to the Guangdong Province Government (China) for support through the program of "Leading Talent of Guangdong Province (Da-Wen Sun)".

\section{Author Contributions}

Zhi-Hong Zhang carried out most of the theoretical analysis and drafted the manuscript, while Xin-An Zeng, Charles S. Brennan and Zhong Han carried out some of the theoretical analyses; Xia-Yu Xiong carried on the Statistical Analysis; Xin-An Zeng, Charles S. Brennan and Margaret Brennan revised the paper. All authors read and approved the final manuscript.

\section{Conflicts of Interest}

The authors declare no conflict of interest.

\section{References}

1. Engel, R.; Stefanovits-Bányai, É.; Abrankó, L. LC simultaneous determination of the free forms of B group vitamins and vitamin $\mathrm{C}$ in various fortified food products. Chromatographia 2010, 71, 1069-1074.

2. Reis, S.F.; Rai, D.K.; Abu-Ghannam, N. Apple pomace as a potential ingredient for the development of new functional foods. Int. J. Food Sci. Technol. 2014, 49, 1743-1750.

3. Carr, A.C.; Vissers, M. Synthetic or food-derived vitamin C-Are they equally bioavailable? Nutrients 2013, 5, 4284-4304.

4. Gallie, D.R. Increasing vitamin C content in plant foods to improve their nutritional valueSuccesses and challenges. Nutrients 2011, 5, 3424-3446.

5. Fenoll, J.; Martínez, A.; Hellín, P.; Flores, P. Simultaneous determination of ascorbic and dehydroascorbic acids in vegetables and fruits by liquid chromatography with tandem-mass spectrometry. Food Chem. 2011, 127, 340-344.

6. Shashirekha, M.N.; Mallikarjuna, S.E.; Rajarathnam, S. Status of bioactive compounds in foods, with focus on fruits and vegetables. Crit. Rev. Food Sci. 2015, 55, 1324-1339. 
7. Cui, J.; Yuan, X.; Wang, L.; Jones, G.; Zhang, S. Recent loss of vitamin C biosynthesis ability in bats. PLoS ONE 2011, 6, e27114.

8. Davey, M.W.; Montagu, M.V.; Inzé, D.; Sanmartin, M.; Kanellis, A.; Smirnoff, N.; Benzie, I.J.J.; Strain, J.J.; Favell, D.; Fletcher, J. Plant L-ascorbic acid: Chemistry, function, metabolism, bioavailability and effects of processing. J. Sci. Food Agric. 2000, 80, 825-860.

9. Valente, A.; Albuquerque, T.G.; Sanches-Silva, A.; Costa, H.S. Ascorbic acid content in exotic fruits: A contribution to produce quality data for food composition databases. Food Res. Int. 2011, 44, 2237-2242.

10. Spínola, V.; Mendes, B.; Câmara, J.S.; Castilho, P.C. Effect of time and temperature on vitamin C stability in horticultural extracts. UHPLC-PDA vs. iodometric titration as analytical methods. LWT-Food Sci. Technol. 2013, 50, 489-495.

11. Roohinejad, S.; Everett, D.W.; Oey, I. Effect of pulsed electric field processing on carotenoid extractability of carrot purée. Int. J. Food Sci. Technol. 2014, 49, 2120-2127.

12. Pedras, M.M.; Tribst, A.A.L.; Cristianini, M. Effects of high-pressure homogenisation on physicochemical characteristics of partially skimmed milk. Int. J. Food Sci. Technol. 2014, 49, 861-866.

13. Jabbar, S.; Abid, M.; Hu, B.; Hashim, M.M.; Saeeduddin, M.; Lei, S.; Wu, T.; Zeng, X. Influence of sonication and high hydrostatic pressure on the quality of carrot juice. Int. J. Food Sci. Technol. 2014, 49, 2449-2457.

14. Unni, L.E.; Chauhan, O.P.; Raju, P.S. High pressure processing of garlic paste: Effect on the quality attributes. Int. J. Food Sci. Technol. 2014, 49, 1579-1585.

15. Lafuente, M.T.; Ballester, A.R.; Calejero, J.; González-Candelas, L. Effect of high-temperatureconditioning treatments on quality, flavonoid composition and vitamin C of cold stored "Fortune" mandarins. Food Chem. 2011, 128, 1080-1086.

16. Polydera, A.; Stoforos, N.; Taoukis, P. Comparative shelf life study and vitamin C loss kinetics in pasteurised and high pressure processed reconstituted orange juice. J. Food Eng. 2003, 60, 21-29.

17. Patras, A.; Brunton, N.P.; da Pieve, S.; Butler, F. Impact of high pressure processing on total antioxidant activity, phenolic, ascorbic acid, anthocyanin content and colour of strawberry and blackberry purées. Innov. Food Sci. Emerg. Technol. 2009, 10, 308-313.

18. Suárez-Jacobo, Á.; Rüfer, C.E.; Gervilla, R.; Guamis, B.; Roig-Sagués, A.X.; Saldo, J. Influence of ultra-high pressure homogenisation on antioxidant capacity, polyphenol and vitamin content of clear apple juice. Food Chem. 2011, 127, 447-454.

19. Barba, F.; Jäger, H.; Meneses, N.; Esteve, M.; Frígola, A.; Knorr, D. Evaluation of quality changes of blueberry juice during refrigerated storage after high-pressure and pulsed electric fields processing. Innov. Food Sci. Emerg. Technol. 2012, 14, 18-24.

20. Odriozola-Serrano, I.; Soliva-Fortuny, R.; Martín-Belloso, O. Impact of high-intensity pulsed electric fields variables on vitamin $\mathrm{C}$, anthocyanins and antioxidant capacity of strawberry juice. LWT-Food Sci. Technol. 2009, 42, 93-100.

21. Odriozola-Serrano, I.; Aguilo-Aguayo, I.; Soliva-Fortuny, R.; Martin-Belloso, O. Pulsed electric fields processing effects on quality and health-related constituents of plant-based foods. Trends Food Sci. Technol. 2013, 29, 98-107. 
22. Meneses, N.; Jaeger, H.; Knorr, D. pH-changes during pulsed electric field treatments-Numerical simulation and in situ impact on polyphenoloxidase inactivation. Innov. Food Sci. Emerg. Technol. 2011, 12, 499-504.

23. Siemer, C.; Toepfl, S.; Heinz, V. Inactivation of Bacillus subtilis spores by pulsed electric fields (PEF) in combination with thermal energy-I. Influence of process- and product parameters. Food Control 2014, 39, 163-171.

24. Oms-Oliu, G.; Odriozola-Serrano, I.; Soliva-Fortuny, R.; Elez-Martinez, P.; Martin-Belloso, O. Stability of health-related compounds in plant foods through the application of non thermal processes. Trends Food Sci. Technol. 2012, 23, 111-123.

25. Ade-Omowaye, B.; Taiwo, K.; Eshtiaghi, N.; Angersbach, A.; Knorr, D. Comparative evaluation of the effects of pulsed electric field and freezing on cell membrane permeabilisation and mass transfer during dehydration of red bell peppers. Innov. Food Sci. Emerg. Technol. 2003, 4, 177-188.

26. Marsellés-Fontanet, Á.R.; Puig-Pujol, A.; Olmos, P.; Mínguez-Sanz, S.; Martín-Belloso, O. A comparison of the effects of pulsed electric field and thermal treatments on grape juice. Food Bioprocess Technol. 2013, 6, 978-987.

27. Quitão-Teixeira, L.J.; Odriozola-Serrano, I.; Soliva-Fortuny, R.; Mota-Ramos, A.; Martín-Belloso, O. Comparative study on antioxidant properties of carrot juice stabilised by high-intensity pulsed electric fields or heat treatments. J. Sci. Food Agric. 2009, 89, 2636-2642.

28. Wu, X.; Diao, Y.; Sun, C.; Yang, J.; Wang, Y.; Sun, S. Fluorimetric determination of ascorbic acid with $o$-phenylenediamine. Talanta 2003, 59, 95-99.

29. Boussetta, N.; Soichi, E.; Lanoisellé, J.-L.; Vorobiev, E. Valorization of oilseed residues: Extraction of polyphenols from flaxseed hulls by pulsed electric fields. Ind. Crop. Prod. 2014, 52, 347-353.

30. Zhang, S.; Yang, R.; Zhao, W.; Liang, Q.; Zhang, Z. The first ESR observation of radical species generated under pulsed electric fields processing. LWT-Food Sci. Technol. 2011, 44, 1233-1235.

31. Torregrosa, F.; Esteve, M.J.; Frígola, A.; Cortés, C. Ascorbic acid stability during refrigerated storage of orange-carrot juice treated by high pulsed electric field and comparison with pasteurized juice. J. Food Eng. 2006, 73, 339-345.

32. Han, Z.; Zeng, X.A.; Fu, N.; Yu, S.J.; Chen, X.D.; Kennedy, J.F. Effects of pulsed electric field treatments on some properties of tapioca starch. Carbohydr. Polym. 2012, 89, 1012-1017.

33. Liu, Y.Y.; Zeng, X. A.; Deng, Z.; Yu, S.J.; Yamasaki, S. Effect of pulsed electric field on the secondary structure and thermal properties of soy protein isolate. Eur. Food Res. Technol. 2011, 233, 841-850.

34. Perez, O.E.; Pilosof, A.M. Pulsed electric fields effects on the molecular structure and gelation of $\beta$-lactoglobulin concentrate and egg white. Food Res. Int. 2004, 37, 102-110.

35. Dabbagh, H.A.; Azami, F.; Farrokhpour, H.; Chermahini, A.N. UV-vis, NMR and FT-IR spectra of tautomers of vitamin C. Experimental and DFT calculations. J. Chil. Chem. Soc. 2014, 59, 2588-2594.

36. Panicker, C.Y.; Varghese, H.T.; Philip, D. FT-IR, FT-Raman and SERS spectra of vitamin C. Spectrochim. Acta Part A: Mol. Biomol. Spectrosc. 2006, 65, 802-804.

37. Luo, W.B.; Han, Z.; Zeng, X.A.; Yu, S.J.; Kennedy, J.F. Study on the degradation of chitosan by pulsed electric fields treatment. Innov. Food Sci. Emerg. Technol. 2010, 11, 587-591. 
38. Wang, J.; Wang, K.; Wang, Y.; Lin, S.; Zhao, P.; Jones, G. A novel application of pulsed electric field (PEF) processing for improving glutathione (GSH) antioxidant activity. Food Chem. 2014, 161, 361-366.

39. Plaza, L.; Sánchez-Moreno, C.; Elez-Martínez, P.; de Ancos, B.; Martín-Belloso, O.; Cano, M.P. Effect of refrigerated storage on vitamin $\mathrm{C}$ and antioxidant activity of orange juice processed by high-pressure or pulsed electric fields with regard to low pasteurization. Eur. Food Res. Technol. 2006, 223, 487-493.

40. Yeom, H.W.; Streaker, C.B.; Zhang, Q.H.; Min, D.B. Effects of pulsed electric fields on the quality of orange juice and comparison with heat pasteurization. J. Agric. Food Chem. 2000, 48, 4597-4605.

41. Elez-Martinez, P.; Martin-Belloso, O. Effects of high intensity pulsed electric field processing conditions on vitamin $\mathrm{C}$ and antioxidant capacity of orange juice and gazpacho, a cold vegetable soup. Food Chem. 2007, 102, 201-209.

42. Lin, S.; Guo, Y.; You, Q.; Yin, Y.; Liu, J. Preparation of antioxidant peptide from egg white protein and improvement of its activities assisted by high-intensity pulsed electric field. J. Sci. Food Agric. 2012, 92, 1554-1561.

43. Wang, K.; Wang, J.; Zhao, P.; Lin, S.Y.; Liu, B.L.; Liu, J.B.; Jones, G.; Huang, H.C. Optimized PEF treatment for antioxidant polypeptides with MW $10-30 \mathrm{kDa}$ and preliminary analysis of structure change. Int. J. Biol. Macromol. 2012, 51, 819-825.

44. Lin, S.Y.; Jin, Y.; Liu, M.Y.; Yang, Y.; Zhang, M.S.; Guo, Y.; Jones, G.; Liu, J.B.; Yin, Y.G. Research on the preparation of antioxidant peptides derived from egg white with assisting of high-intensity pulsed electric field. Food Chem. 2013, 139, 300-306.

45. Sun, J.; Bai, W.; Zhang, Y.; Liao, X.; Hu, X. Effects of electrode materials on the degradation, spectral characteristics, visual colour, and antioxidant capacity of cyanidin-3-glucoside and cyanidin-3-sophoroside during pulsed electric field (PEF) treatment. Food Chem. 2011, 128, 742-747.

46. Liu, Z.W.; Zeng, X.A.; Sun, D.W.; Han, Z. Effects of pulsed electric fields on the permeabilization of calcein-filled soybean lecithin vesicles. J. Food Eng. 2014, 131, 26-32.

47. Wang, M.S.; Zeng, X.A.; Sun, D.W.; Han, Z. Quantitative analysis of sublethally injured Saccharomyces cerevisiae cells induced by pulsed electric fields. LWT-Food Sci. Technol. 2015, 60, 672-677.

48. Klimczak, I.; Gliszczyńska-Świgło, A. Comparison of UPLC and HPLC methods for determination of vitamin C. Food Chem. 2015, 175, 100-105.

49. Gu, F.; Kim, J.M.; Hayat, K.; Xia, S.; Feng, B.; Zhang, X. Characteristics and antioxidant activity of ultrafiltrated Maillard reaction products from a casein-glucose model system. Food Chem. 2009, $117,48-54$.

50. Yen, W.J.; Wang, B.S.; Chang, L.W.; Duh, P.D. Antioxidant properties of roasted coffee residues. J. Agric. Food Chem. 2005, 53, 2658-2663.

(C) 2015 by the authors; licensee MDPI, Basel, Switzerland. This article is an open access article distributed under the terms and conditions of the Creative Commons Attribution license (http://creativecommons.org/licenses/by/4.0/). 